\title{
China's Policy Dynamic Adjustment Mechanism Based on Evolution Characteristics of Strategic Emerging Industries [ $\left.{ }^{*}\right]$
}

\author{
Hongmin Liu, Yichao Han* and Weiwei Liu \\ School of Economics and Management, Zhejiang University of Science and Technology , \\ Hangzhou Zhejiang 310023, China
}

Keywords: Strategic emerging industries (SEI); Emerging technologies; Evolution characteristics; Dynamic adjustment mechanism

\begin{abstract}
The typical periodic evolution is the characteristics of strategic emerging industries (SEI), and the development of SEI opens the "window of opportunity" for the establishment of the industry leaders and the late-development countries to realize economic catch-up. However, the characteristics of externality and technology, market and organization of uncertainty weaken the strategic function of SEI, and the development of SEI needs cultivation of industrial policy. Nowadays there are some "fragmentation" and "sticky" phenomenon of the current policy problems in the promotion of China's SEI. Therefore, it has great practical significance to establish dynamic policy chain conforming to industry development path and covering different stages of development of emerging industry in order to effectively grasp the "window of opportunity" of SEI.
\end{abstract}

\section{Introduction}

Strategic emerging industries (SEI) are the emerging industries which are related to the national economy overall situation, and may become the dominant or pillar industries (Forbes, 2011; Lin \& Hsieh, 2014) ${ }^{[1,2]}$. The development of SEI is the national strategic layout and is to speed up the upgrading of industrial structure and change the pattern of economic development in China. The development of strategic emerging is also enhancing China's capacity for independent innovation and industrial competitiveness of major initiatives. Compared with general industries, strategic emerging industries always tend to have the Features called "four high" like high technology content, high investment, high-growth and high-risk. And the Features of SEI need the government to play a unique role to establish an effective mechanism consisting of guidance, coordination, incentive and constraint to promote the development of SEI from the different levels of technical $\mathrm{R} \& \mathrm{D}$, market cultivation, industrial planning and so on ${ }^{[3]}$.

Governance and innovation of emerging industries is a big challenge faced by modern government(Stilgoe, J. et al., 2013; Buenstorf et al., 2015) ${ }^{[4,5]}$. Strategic emerging industries always tend to have the multiple uncertainty of technology, market and industrial organization, which have the typical characteristics of periodic evolution(Utterback \& Suarez,1993; Nelson,1994; Benner, $2010)^{[6-8]}$. The regularity and dynamic process of industry evolution require the policy itself owned proactive and adaptive characteristics, and the policy must be adjusted with the industry evolution process adaptively. Only in this way, the stage characteristics of SEI can be grasped overall by the policy subject, and the policy subject can provide timely and effective policy support to the development of SEI. As shown in Figure 1, a stochastic network model is used to describe the evolution process of strategic emerging industries. Nodes represent industry system state, state 1 corresponds to the emerging technology was just emerging and strategic emerging industries into the seed germination stage. 2-5, corresponding to the different stages of strategic emerging industries from the birth, growth and development to maturity and stability. State 6 represents the transformation and upgrading of strategic emerging industries. Status 7 indicates that the collapse or decline of strategic emerging industries which may occur at various stages of industrial evolution. In the process of fostering strategic emerging industries, policy subject should be based on strategic emerging industries within the specific evolution stage, through differences in policy guidance to reduce the uncertainty in the process of the development of strategic emerging industries. 


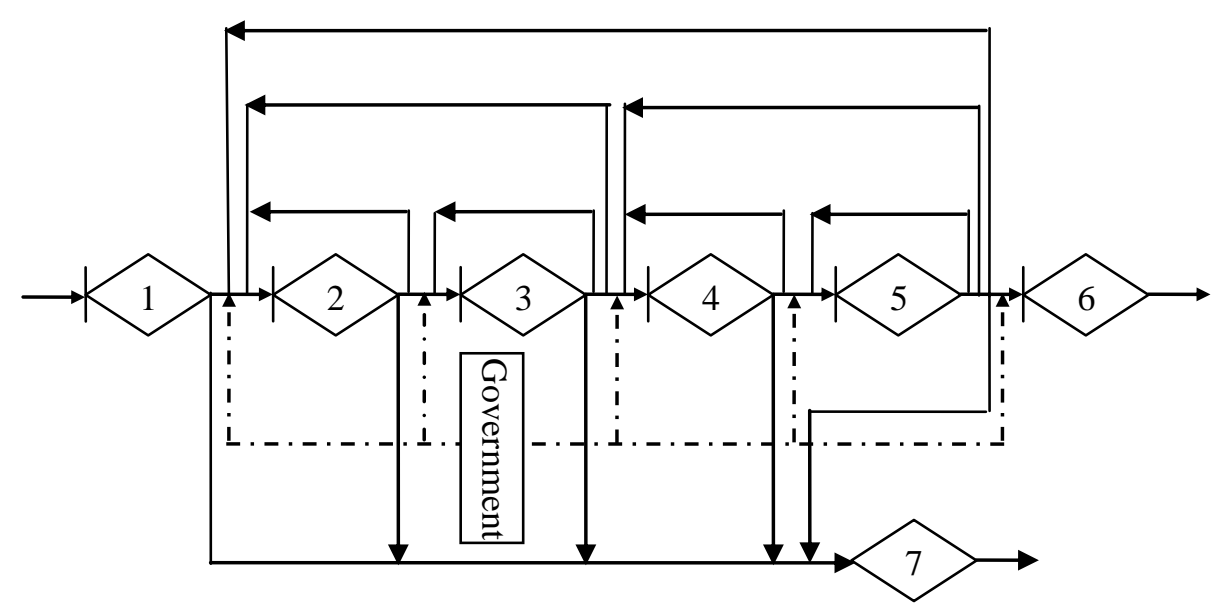

Figure. 1 GERT model of strategic emerging industry cultivation

Combining with the development of China's strategic emerging industries in recent years, that can be found that there are many problems in the formulation and implementation of policies to promote the development of SEI in current China. The policy adjustment is incoherent and forward-looking because of some "fragmentation" and "sticky" phenomenon of the current policy problems ${ }^{[9]}$. So, it has important practical significance to build the policy chain and its dynamic adjustment mechanism of corresponding to the development track height of SEI and covering emerging industries in different stages in order to effectively grasp the "window of opportunity" of SEI.

Since 2010, The Chinese governments chose seven key industries of energy conservation and environmental protection industry, a new generation of information technology industry, biological industry, high-end equipment manufacturing industry, new energy industry, new material industry and new energy automobile industry as the strategic layout of China's SEI. With the economic globalization and market competition intensified, the importance of SEI seems more and more important. It is imperative that build a dynamic hybrid policy chain on the basis of grasping of the features of the related industry development and depending on different stages of emerging technologies to break through the limitations of a single policy tools and improve the policy system of dynamic adaptability.

\section{Literature review}

Strategic emerging industry itself is not a standard economic concept, it is the combination of the two concepts of strategic industries and emerging industries. The mainstream concept is used "emerging industries" in other countries, and the emerging industries are defined mainly from the new market and new services, enterprise's life cycle, business and employment growth, paradigm shift, etc. ${ }^{[10]}$

According to the characteristics of SEI, scholars discussed a number of characteristics like strategic, uncertainty (Technology, market and organization), positive externalities (R\&D, industrialization) and complexity (Technology, industrialization) so that they form consensus mostly. Hefa Song (2010) $)^{[11]}$ think strategic emerging industry is the emerging high penetrability of new and high technology industries and it has industry connotation and characteristics including pilot, friendliness, guidance, dependence, strategic and so on. Guomin Sun $(2014)^{[10]}$ think the distinctive characteristic of SEI mainly embody in seven aspects containing strategic position, affect the overall situation, forward-looking technology, market risk, sustainable development, ecosystem industry, regional competitive and the like. Zhonglin Fei, $(2013){ }^{[12]}$ considered that SEI also have the characteristics of a series of phases consisting of introduced period, growth period, mature period and adjustment period according to the general law of the life cycle process gradually development. Bin $\mathrm{Hu}(2014)^{[13]}$ divided SEI into four stages like incubation period, growth, development and decline from the technology innovation, organization pattern, the industry chain 
and market situation of different characteristics of the four dimensions.

After in-depth analysis for characteristics of the evolution of SEI, it shows that SEI are often born by radical technology. Sen (2011) ${ }^{[14]}$ said India's software industry is promoting the industrial international competitiveness by radical technology innovation. Ehrnberg $(1995)^{[15]}$ studied the evolution characteristics of paroxysmal technology systematically. Radical technology embodied in frost $S$ curve jump discontinuity point .It can be either a technology life cycle transferring to another life cycle, it can also be a cycle transferring to another cycle from a technology life cycle, as shown in figure 2.

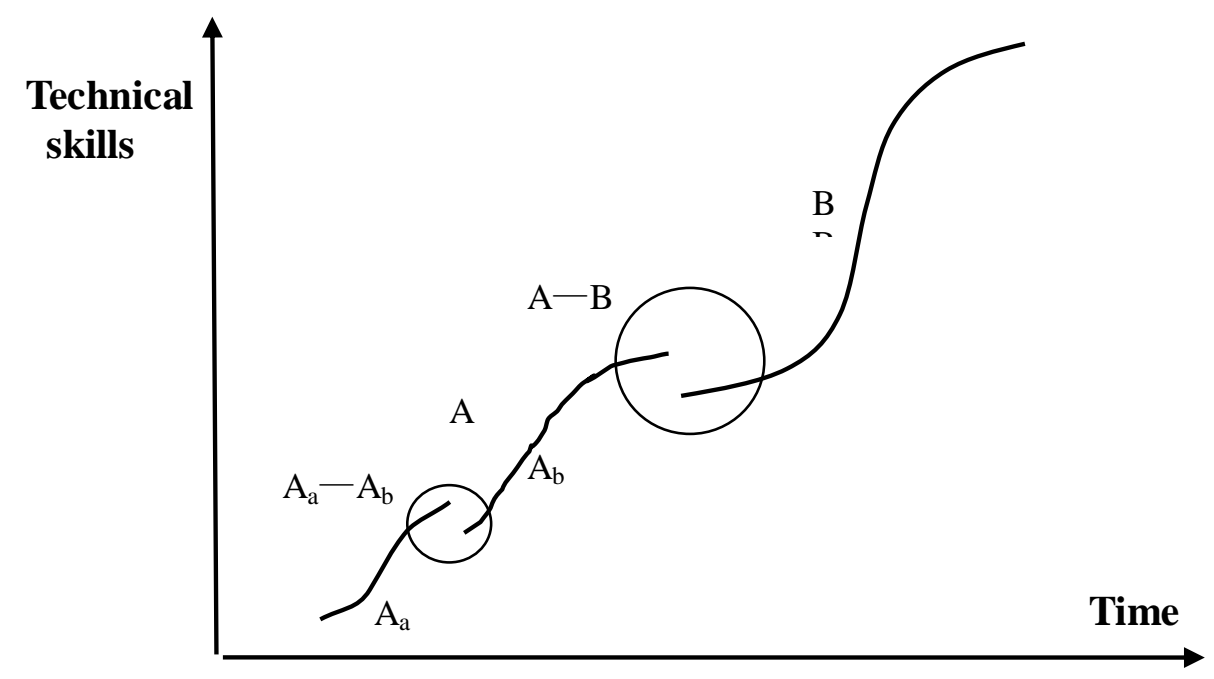

Figure 2. Technology cycle and evolution characteristics of radical technology

There are two aspects for related researches about guidance and incentive policy of SEI. First, relating to the current evaluation of the policy system of China's SEI, Zhibiao Liu(2011) ${ }^{[16]}$ pointed out that s SEI were driven by policy guidance and market. To some extent, the motivated of policy guidance is larger. However, there were bias like "offside and dislocation" in current policy system. And emerging industries policy tools in all stages of development is quite lack to agree with strategic .Wenjun $\mathrm{Li}(2014)^{[17]}$ think that it is a need to integrate existing technology policy, merge similar policy and force policy. Liu(2011) point out that bull management and lack of coordination is currently China's emerging industries to carry out the innovation policy issues to be resolved ${ }^{[18]}$. Second, Yingming Li(2008) [19] indicated that policy combination was important to policy adjustment about policy adjustment mechanism. Governments need to have both decided to each policy tools, more attention should be paid to the collocation of different policy tools and improve the efficiency of policy constantly in the process of trial and error. Han Xia \& Keshi Zhu(2014) ${ }^{[20]}$ point out that the optimization of the structure of $R \& D$, strengthen organization and coordination and planning are the keys to strengthen the booster on the strategy and policy choice of intellectual property. Some research has explored actively in the strategic emerging industry policy system evaluation, policy mechanism and policy adjustment mechanism, etc. But existing research is less involved in the policy adjustment mechanism that conformed the development characteristics and different development stages of SEI.

\section{Problems with existing China's SEI policies}

Combined with development of SEI in China in recent years and through the strategic emerging industry overall policy like industrial technology policy, market cultivation policy, tax policy, special policy and so on of framework of the system analysis, you can realize in the formulation and implementation of policies to promote the development of SEI aspect also has many problems currently and current policy system cannot cover and adjust to the new features of SEI, the new demands, agree with strategic. The development characteristics and requirements of emerging industries in each stage lack of policy tools relatively, policy coordination mechanism is not perfect, 
some of the macro industry policy lack of a clear and implement the main responsibility of the subject and it is difficult to promote the implementation of China's SEI policies.

The structure problems of SEI policies. The relevant industry policies exist unreasonable structure and lack of dislocation phenomenon in facing the different developmental stages of SEI. A lack of interoperability is between policy makers and implementers to make relevant policy to present "fragmentation" phenomenon, the integration of policy system is even missing. The technical route of strategic emerging industries has diversity and uncertainty. In such a scenario, dynamic organic coupling relationship is forming between policy and policy so that various policies generates positive interaction effect and eventually form a kind of effective policy together. However, in the real industry development environment, due to the division of the functions of the government, financial resources, power resources, information resources and system resources, actually the scattered in different levels of government departments control, different departments in the policy formulation and implementation lack of coordination and even constraint on each other .So the absence and dislocation of policy of the whole system in strategic emerging industry evolution path present a phenomenon called distribution "fragmentation" .

The lag problems of SEI policies. The bodies of SEI policies pay attention to the new policy that is lacking of continuous tracking of dynamic evolution of SEI so that policy present phenomenon named "sticky" and can not adjust in time as the change of industrial environment. Such as photovoltaic industry, photovoltaic industry has been supported by government policies all along. The capacity expansion of the superposition of policy support is far outweighs to the absorptive capacity of the domestic market. Enterprises rely on the international market overly so that it pretends to be a struggling by the financial crisis and political environment as well as many other factors and finally rely on the government to use of public resources. From that If industrial policy support excessively, the country's financial resources is not only a large number of consumption and also will strengthen The dependence on policy to the industry to loss vitality and competition ability. So we have to pay special attention to the efficiency of the policy, when the policy environment changes, perform continuous is bound to lead to policy cost is greater than the benefits. The policy's exit and import are equally important to avoid the policy "sticky" appearance timely.

The coordination problems of SEI policies. The bodies of China's SEI policies aye lacking of forward-looking, consistency and continuity in terms of policy adjustment (reserve, issued, implementation and the end). Such as in the field of electric vehicles, to accelerate the industrialization of electric vehicles, the policies must include subsidies, infrastructure, oil tax, improvement of the traditional fuel vehicle emissions standards and so on. It can neither be lacking and should accomplish policy between each other echo. Industrialization over the past few years, but the policies are still relatively fragmented and conflicting policies is from different departments, policy and policy is over trifling so that delaying the development of the industrialization of electric vehicles.

\section{Policy dynamic adjustments}

With the economic globalization and market competition intensifying, strategic emerging industries is more important. Both from the significance of national economic of social development and the law of industry development, strategic emerging industries need to foster and guide from the government. Priority is on the basis of grasping of the features of the related industry development depending on different stages of technology of emerging industries to build dynamic mechanism of industrial policy adjustment to adapt to the evolution of strategic emerging industry development.

The analysis of the effects and sensitivity of industrial policy. Studies have shown that ${ }^{[21]}$ industrial technology policy, industrial investment and financing policy, market cultivation policy, international cooperation policy and the like are considerable differences in their sensitivity in different evolution stages of SEI. In view of evolution characteristics of SEI, policy subject should study the law of evolution of SEI in the practice of the policy management system and analysis industry technology policy, international cooperation, industry investment and financing 
policy and market cultivation in different development stages of sensitivity to build a strategic emerging industry and technology trajectory conjunction and can cover its dynamic mixed policy chain in different development of stages . Advantage of the synergy of different types of policy, manage effectively the cycle life of policy and improve dynamic adaptability of the policy system. One of the preconditions of building dynamic hybrid policy chain is that the decision-making must have the ability according to the characteristics of periodic evolution by SEI and timely select the appropriate tools from its policy tool box and composite applications. The process of policy choice is often policy study. In order to cross the study of national policy more effectively, the main body of domestic policy need build environmental scanning and analysis platform used to monitor and analyze Europe and the United States, Japan and South Korea policy evolution trends and innovation model. As shown in figure 3, these countries put the effective development of promotion policies, industrial layout policy and market cultivation policy system to collect and inductive analysis and use the knowledge management tool on these countries industry development background, policy planning process, the effect of policy implementation and policy end model such as refining and research on the key points of each part. On this basis, the knowledge base of the best policy practice should be built according to the periodic evolution features of emerging technologies, and the knowledge base should be one of the important sources of innovation as the main body of policy planning.



Figure 3. The international level policy environment scanning and analysis platform

The research of the sensitivity of SEI policies tools for different development stages of SEI shows that the cost and effect of different industrial policies are different and the sensitivity of SEI policies are also different. For different development stages of the strategic emerging industry policy tools research shows the cost and effect of different industrial policies are different, the role of sensitivity, the sensitivity of industries is different and stage of development of applicable industry. For example, the same tax incentives is different, in the role of the developmental stages of the strategic emerging industries there are considerable differences in their effect; Fiscal subsidy compensated the costs and benefits of risk of the externality of enterprise innovation in a certain extent. By contrast, tax incentives can induce enterprise's R\&D activity in a larger extent. Compared with individual firms, the sensitivity of effect of the same policy on enterprise alliance body is more significant, at the beginning of the development of SEI, the government should take the policy resources advantage into production association. Policy subject need not only study the sensitivity of the single policy and also should pay attention to analyze policy combination force and the speed of the role of strategic emerging industry development. It need to emphasize that the policy performance of vitality lies in the dynamic adjustment of the relationship between government and market, the market is advancing technical innovation and new industry development of the most powerful motivation. Financial support should be more embodied in the "before the competition". 
The construction of dynamic policy combination chain. The breakthrough of major technical is the key to the sustainable development of strategic emerging industry, Technical mutations is associated with a large number of uncertainties. The government shall establish a process of the efficiency node evaluation system in order to make the government timely resources dynamically to the policy according to the industry's latest evolution trend redistribution. Therefore, policy dynamic adjustment is focused on the dynamic combination. It both want to consider the strength of each policy tools and more should pay attention to the collocation of different policy tools. Policy should be a dynamic adaptive process, the government incentive policies relating to industry must be based on the strategic emerging industry of new forms, new patterns and timely adjust. The governments need to interact with enterprises to carry out deeply and constantly improve the efficiency of policy in the process of trial and error. Policy adjustments in essence is a government decision makers to decision-making behavior and is the policy of redistribution of resources; Due to the policy resources limited, the government shall drain resources from the old policy system according to industry development situation consciously, introduced to the new policy architecture, the policy framework of conversion timing, transformation and conversion rate will have decisive impact on the efficiency of the whole policy system.

The construction of policy window triggering mechanism. Based on the evolution characteristics of emerging industries, the life of the policy cycle must be done well, including the policy agenda establishment, policy scheme planning, policy window opening, and policy window closes etc. Kingdon (2004) put forward the concept of "the policy window", he emphasized the policy subject timely open or close the window of the policy in key point in the evolution of the technical environment in order to make policy to play the best effect ${ }^{[22]}$. The policy window triggering is the catalyst of policy implementation or termination, every link of related process will be according to certain rules to start if triggers once activated. Triggering mechanism depends on the interaction of three factors, such as the landmark events in the history of emerging technology development path, policy planning and its implementation rules and policies related to financial resources. Therefore, the study of policy window opening and closing of trigger mechanism has important application value. The efficiency of the policy needs to be special attention; the policy windows should be opened or closed according to the different evolution stages.

\section{Conclusion and policy implications}

The appearance of emerging industries provides the opportunity for Chinese enterprises to surpass competitors within the corners. Nowadays there are some "fragmentation" and "sticky" phenomenon of the current policy problems in the promotion of SEI in China. Therefore, it has great practical significance to establish dynamic policy chain conforming to industry development path and covering different stages of development of emerging industry in order to effectively grasp the "window of opportunity" of SEI.

Policy subject should study the evolution of SEI in the practice of the policy management systematically. The effects and sensitivity of industrial policies such as industrial technology policy, international cooperation policy, industry investment and financing policy, and market growth should be analyzed at the different developmental stages of SEI. Policy dynamic combination chain should be established in order to form the dynamic organic coupling body among the different policies.

\section{Acknowledgement}

[*]Project supported by the National Social Science Foundation of China(NO.16BGL161)

\section{Reference}

[1] Forbes D P, Kirsch D A. The study of emerging industries: Recognizing and responding to some central problems [J]. Journal of Business Venturing, 2011, 26(5): 589 - 602. 
[2] Lin F R, Hsieh P S. Analyzing the sustainability of a newly developed service: An activity theory perspective [J]. Technovation,2014,34(2): 113-125.

[3] Sun Y, Liu F. A regional perspective on the structural transformation of China's national system since 1999 [J].Technology Forecasting and Social Change, 2010, 14(9):1311-1321.

[4] Buenstorf G, Fritsch M, Medrano L F. Regional Knowledge, Organizational Capabilities and the Emergence of the West German Laser Systems Industry, 1975-2005[J]. Regional Studies, 2015, 49 (1):59-75.

[5] Stilgoe J, Owen R, Macnaghten P. Developing a framework for responsible innovation [J]. Research Policy,2013,42(9):1568-1580.

[6] Utterback J M, Suarez F F. Innovation, competition, and industry structure [J]. Research Policy, 1993, 22( 1): 1-21.

[7] Nelson R R. The Co-evolution of technology, industrial structure, and supporting institutions [J]. Industrial and Corporate Change,1994,3( 1) : 47-63.

[8] Benner M J. Securities Analysts and Incumbent Response to Radical Technological Change: Evidence from Digital Photography and Internet Telephony [J], Organization Science, 2010, 21(1): 42-62.

[9] Liu F, Simon D F, Sun Y, et al. China's innovation policies: Evolution, institutional structure and trajectory [J].Research Policy, 2011, 40(7):917-931.

[10] Sun G. Strategic emerging industry definition: a literature review [J].Management Science and Research, 2014, (2):43-46.(in Chinese)

[11] Song B, Wan J, Ren Z. The connotation of the strategic emerging industry in China characteristics, choice of industry research and development policy[J]. Promote the development of science and technology, 2010, (9):7-14. (in Chinese)

[12] Fei Z, Wei W. Support the government policy of strategic emerging industries - based on the industry life cycle considerations[J].Science Technology Progress and Policy2013,(3):104-107. (in Chinese)

[13] Hu B, Wang $\mathrm{H}$. The development of strategic emerging industry demand innovation policy framework system design [J]. Industrial technology economy, 2014, (5):117-123. (in Chinese)

[14] Sen T K, Ghandforoush P. Radical and incremental innovation preferences in information technology: an empirical study in an emerging economy [J]. Technology Management \& Innovation, 2011, 6(4):33-45.

[15]Ehrnberg E. On the Definition and Measurement of Technological Discontinuities [J]. Tecnovation, 1995, 15(7): 437-452.

[16] Liu Z. Banking functions of science and technology building: the key problems of commercial Banks to support the development of strategic emerging industries [J].Social Sciences in Nanjing,2011,(4):1-8. (in Chinese)

[17] Li W. Technology policy of strategic emerging industries [J].Forum on Science and Technology in China, 2014,(4):51-55. (in Chinese)

[18] Liu F, Simon D F, Sun Y, et al. China's innovation policies: Evolution, institutional structure and trajectory [J].Research Policy, 2011, 40(7):917-931

[19] Li Y. The economic efficiency of public policy and the regional innovation service platform construction [J].Science of Science and Management of S\&T, 2008, (11):49-56. (in Chinese)

[20] Han X, Zhu K. The analysis of the policy orientation of strategic emerging industry development[J].Economic issue,2014,(3):1-5.(in Chinese)

[21]Levén P, Holmström J, Mathiassen L. Managing research and innovation networks: Evidence from a government sponsored cross-industry program [J].Research Policy, 2013, (9):1001-1012.

[22] Kingdon J. W. Agendas, alternatives, and public policies (2nd Edition). Longman, 2011. 